\title{
Distance Education and Lifelong Learning
}

A Brazilian time-honored study case approach

\author{
Rosa Vicari and Ricardo Azambuja Silveira \\ Universidade Federal do Rio Grande do Sul Brazil; Universidade Federal de Pelotas - Brazil
}

rosa@inf.ufrgs.br; rsilv@ufpel.tche.br

Abstract: This paper presents some considerations on the theoretical position concerning the use of technology for continued education and two case studies. The first one reports a distance post-graduation course to qualify teachers who work in grade school and high school to prepare them for the use of information technologies in their classes. The second one reports the distance teaching project, based on open source software, created for people that have no access to regular classes. Both are activities at UFRGS - Federal University of Rio Grande do Sul, Brazil.

Key words: distance learning, Lifelong Learning, pedagogical model, technological model,

\section{INTRODUCTION}

Computer Science, along with Psychology and Education, have been improving computational tools for individualized teaching, with new approaches to and perspectives of the deployment of computer science in education, influenced for the past 15 to 20 years, by the advances in cognitive science. As a consequence of this influence, education has been more focused on learning rather than teaching. Knowledge is now considered as something socially built through action, communication, and the student's consideration. Education based on technology, known as elearning (Rosemberg 2001), and distance education, in its present state, applies very well to this educational concept. 
Educational institutions and other organizations began to use computational tools as an instrument to implement educational projects of distance learning, aiming not only for the improvement of so-called conventional teaching, but also for projects in lifelong learning. Very often these organizations tended to use the already available technological resources to insert new resources without an adequate pedagogical project.

The use of technology in educational projects offers several advantages, such as, greater interactivity between students and teachers; the creation of multidisciplinary teams and virtual dynamics; the cutting of operational costs; and more. However, inserting this type of system may result in all sorts of challenges. As technologies become more and more complex, demanding a greater effort for its insertion, the evaluation of its impact becomes indispensable not only when it is drawn from technological and financial aspects, but also when it considers aspects linked to the organization and its capacity to accept and support the changes due to a new technological reality.

According to Rosemberg (2001), the simple use of technological resources without an appropriate pedagogical project, and without the proper adequacy of the organization, results generally in excessive static and directive teaching environments. From this comes the necessity to establish implantation models for learning environment projects with an adequate pedagogical proposal and the correct use of disposable technology to better fit the objectives of each organization.

In order to be integrated and keep their employment in the 21 st century, individuals need to develop a succession of capacities such as selfadministration, organization of their own work, assumption of responsibilities, learning on their own, working in teams, and generally developing a flexible and adaptable approach to solve new problems and face new tasks. They would also need to prepare for technological innovations and its pedagogical consequences. In this way, continued education has an important role in the dissemination of the technological culture, in the development of communication skills, and in the unfolding of a capacity to work with a method.

With the new technologies there is hope to produce better teaching with more quality and cultural relevance to the people, granting a new knowledge level to those whom the traditional structures of the teaching system did not convey to higher schooling levels.

This paper presents some considerations on the theoretical position concerning the use of technology for continued education and presents two case studies as actions for continued studies at UFRGS - Federal University of Rio Grande do Sul, Brazil. 


\section{IN SEARCH OF A PEDAGOGICAL MODEL}

The educational activity proposed for a computational environment (to be used in distance education) should not sustain errors from traditional teaching. We should keep in mind the peculiarities of distance education, mainly when it comes to the nature of its objectives and the characteristics of its clients, constituted mostly by young people or adults in a distributed establishment.

Traditional Education depends upon the teacher: it is he who speaks, explains, acts and takes decisions, determines what should be learned, establishes the learning rhythm, the study schedules and the disciplinary rules.

For a long time it was believed that the human being attained the maximum of his intelligence at the age of thirteen, and that the mental age of the average person was settled at this time. Lifelong education come into view during the second half of the twentieth century from the study of adult psychology and the adaptation of teaching methods to meet the people's reality. Lifelong education was considered necessary due to the complexity of life in contemporary society, by the great sum of lifelong understanding, the constant change of social environments and the possibility of self improvement for the rest of one's life. (Mizukami, 1977)

In Jean Piaget's books, we may find some important studies to form a guiding example on how to employ methodologies in the development of human resources. We can synthesise the Constructive-Cognitive approach with Piaget's main theory such that a person is considered as an open system in a successive re-structuring process that searches for a final stage, yet never entirely achieved. In this context, knowledge is considered as a continuous construction characterised by the formation of new structures that did not exist before in the individual, consequently human knowledge is essentially active.

The educational process, according to the theory of development and knowledge, has an important role as it provokes unbalanced situations for the students in the level of development in which they are found, in a way that a progressive construction of notions and operations becomes possible while the individual at the same time lives intensively each step of his development.

The compatible teaching with the Piaget's theory (1977) has to be based on analysis, research, investigation, and the resolution of the student's problems. This matter differs from the behaviourist approach.

According to Mizukami (1977) there is no pedagogical model in Piaget's theory, it is an 'understanding' theory. Nevertheless, some basic 
presuppositions may stand out that are fit for planning teaching/learning situations, based on constructivism.

- The action of the individual is the centre of process, essentially based on investigation;

- Teamwork acquires theoretical consistency;

- Teaching material and environment must be challenging and promote the motivation for investigation;

- The use of audio-visual resources is not sufficient to develop operating activities. The experiences should not be done to the students, but by them;

- Programmed teaching leads to learning, but not creating;

- An individualized teaching method is coherent if there is respect for its own rhythm, way of action and creation for the student, involving programs, techniques and schedules, sufficiently flexible and adaptable to the student's conditions.

In the same way as Piaget's constructivism, the argument on information processing deals with the conception of mental representation, with a primary study purpose which is the genesis, the development and transformation of these representations (Eysenck and Keane 1994) and (Simon 1981). The cognitive psychology of the information processing differs in some constructivism points, although it involves some presupposed basics, such as the idea that an agent acts upon his thoughts, emotions, and feelings, just like the emphasis given to the scientific method as an object of study, neglected by psychoanalysis and by behaviourists.

Cognitive psychology appeared in the mid-sixties, considered as a postbehaviourist psychology by its empirical, theoretical, methodological and scientific ways, which it inherited from behaviourism, although yet opposing behaviourism in the sense that it does not restrict the studies to the stimulate/answer, stimulus/response model. Researchers in this area have developed methods of systematic behaviour observation in their search for the construction of axiomatic models. This experimental foundation and even the construction of computational simulations have brought the area close to artificial intelligence (A.I.), which also studies how mental processes occur and what kind of architecture can support them.

Human beings at this moment are seen as information receiver, transmitter, and dealer organisms and, therefore, they have processes that present specific characteristics, easy to be explained. In this stream of psychology, the human being is identified as an active person in his environment and has an auto-regulation mechanism (cybernetics) and also a shortage in these mechanisms and in those of information treatment. The assumed task by the cognitive psychologist then becomes that of an 
ecological character: it has to discover the cognitive function of the individuals with the intention of improving their abilities.

According to (Eysenck and Keane 1994), cognitive psychology is concerned with the processing of information and includes a variety of processes, such as attention, perception, learning and memory.

Although both cognitive matters (constructivism and information processing) compete in their view of mental representations, assuming just two constitutive atoms of the mind. The research differs when it comes to the constructivism taking on the existence of primitive cognitive structures, which change within a previously defined plan of logical structures that appear in a progressive sequence during human development, while the information processing matter believes that there is no previously defined, genetic, logical structure.

Another divergence concerns the impetrated analysis level on both matters. The attempts on explaining the information processing matter are microscopic, searching for the processes and the mental strategies of the subjects to configure the representation of the world that surrounds them. The constructivist is macroscopic in its analysis checking on the results on interactions between the proper cognitive structures on the individuals development phase and each ones own reality. Both matters provide important subsidies for the conception of computational teaching environments once they become, in a sense, the individuals' main instrument of action as a student with his surroundings.

As observed, the question on the psycho-pedagogical principles is quite complex and makes it difficult to prescribe an ideal solution that may be applied to each and every subject matter, and each particular situation. It may be a student or a teacher that directs the usage or implementation of a computational teaching tool.

\section{IN SEARCH OF TECHNOLOGICAL MODEL}

With the evolution of computer science in education, the computational teaching environments have become an excellent alternative for distance learning. The present state of art of the web and multimedia has improved the development of teaching environments based on client-server architectures. In a special way, the popularisation of the Internet, and the development and standardization of protocols and services, makes it quite attractive for the distance learning popularity.

The main idea about distance education is the development of environments and of methodologies that are favourable for remote learning, that is, that one or more students may go through learning experiences in a 
different location from where the environment and instructional resources are found. This architecture configures an excellent alternative solution for Distance Learning.

The distributed environments for learning make available to the student all the multimedia resources frequently found in the traditional teaching environments with an adequate speed and quality performance, bringing in the advantage that the system may take hold of resources that are not materially available for their tools.

The learning systems based on the web are a perfect alternative for distance learning by the fact of placing pedagogical contents available to several students, also making learning opportunities possible to a bigger number of people. (Sherry 1981)

Analysing several Distance Learning tools like:

- http://www.hera.nied.unicamp.br teleduc;

- http://www.psico.ufrgs.br/lec;

- http://www.eduweb.com.br/aulanet;

- http://www.equitext.pgie.ufrgs.br/;

- http://www.learningspace.org/;

- http://www.webct.com.

In this paper we discuss two case studies using TELEDUC an open source free licensed learning environment, and LEARNING SPACE, a commercial learning environment. These kinds of learning environment use to be limited from the flexibility and adaptability point of view and did not suitably consider the most modern learning matters in a constructivist sense. Research, in this matter, turns towards three great courses:

- The use of adaptive WWW pages that makes use of a method to modify the contents of the pages to adapt them to the student's attitudes.

- the use of WWW systems based on the traditional architecture of Intelligent Tutors (ITS) (Vicari 2003), (Giraffa and Vicari 1999) with a WWW interface, including sometimes collaborative learning mechanisms (Schwartz et al. 2001).

- The architectures that make use of intelligent agents (Silveria and Vicari 1999).

The most recent advances in the field of 'Intelligent Learning Environments' have proposed the use of 'A. I'. techniques using architectures based on agent societies (multi-agent systems). The introduction of the A.I. techniques in these environments has the purpose of favouring modelling mechanisms of the learning process and the representation of the students' cognitive state.

The principles of multi-agent systems have shown adequate potential for the development of computational learning tools, due to the fact that, because of their nature, the teaching and learning problem can be 
approached in a cooperative manner. Learning environments based on multi-agent architectures make it possible to support the development of more interactive and adaptable systems in an even more vigorous way and with lower costs, making them more attractive and efficient from a pedagogical point of view.

\section{CASE STUDIES}

Next follows the presentation of two experiments carried out in Continuous Education projects. These distinct experiments were selected due to the fact that we believe that both have certain singularities that are relevant for this paper.

\section{Post-Graduation course for teachers' qualification}

This course lasted from October 2000 to May 2002. Its aim was to qualify grade school and high school teachers in the use of information technologies in their classes. 68 students from Brazil, Uruguay and Argentina took part in this course.

The student's profile verification resulted in the following: 67 students have a computer at home, but only 14 were connected to the Web. $65 \%$ of the students were familiar with the English language. 69\% of the students were well aware of the use of text editors, and 55\% used to be regular users of on-line systems. During the first week of the course there were meetings where the students were assembled at UFRGS to develop activities with the objective of training them on the use of computational resources.

Throughout the semester, each discipline had asynchronous and synchronous activities. The latter was done by using video conference facilities (for small groups), video streaming and chat tools. The supporting environment Learning Space was used to aid the asynchronous activities and a Web server, where each student had his own working space and organized his own web portfolio. In each discipline, the students took the aid of a monitor ( $\mathrm{PhD}$ students from UFRGS) that supported the study process and attended the students in their needs to use computational tools. 


\section{Results}

After the end of the theoretical and practical classes, the students developed their final work under the orientation of a teacher. From the 68 students that began the course, 56 concluded it successfully.

At the end of each stage there was an evaluation of the course. The evaluation involved teachers, monitors and students, and concluded that the course obtained its intended goals. Teachers, monitors and students all came to the conclusion that the experience was positive, attributing a relevant portion of responsibility due to the success of prompt reactions and response to the help requests and consultations by the students that received an answer in less than four hours.

Because the students used to work in professional activities during the course time, it was suggested that in the next editions there would be a reduction of the weekly burden of activities and the disciplines would be organized in three trimesters. It was also suggested that the number of classmates should be reduced.

Table 1.Students answers about different items.

\begin{tabular}{lc}
\hline \multicolumn{1}{c}{ Query } & Rate \\
\hline Contents adequacy to the course & 6,74 \\
Contents & 5,97 \\
Material quantity & 7,06 \\
Discussion opportunity & 5,25 \\
Contents integration & 6,84 \\
Video transmission technology used in course & 4,63 \\
Other technologies like e-mail, chat or WWW server used in course & 5,92 \\
Utility of the material of this course in the future & 4,78 \\
How much did you learn in this course & 8.47 \\
How much did you like this course & 8,42 \\
How much effort did you place in this course & 8,55 \\
How valuable was this course for you & 8,40 \\
\hline
\end{tabular}

An evaluation questionnaire was distributed to the students where it was requested a rating from zero to ten for each indicator. Their answers can be seen in Table1.

Table 2 presents the results of another evaluation that points out the schedule load, its distribution and the period of the course, as the rate of answers of all three factors came out as regular $(3,82)$. 
Table 2.Course general evaluation.

\begin{tabular}{ll}
\hline Query & Rate \\
\hline Curriculum & 4,38 \\
Discipline sequence & 4,24 \\
Schedule load of the course & 3,65 \\
Schedule load distribution between disciplines & 3,49 \\
Course period & 3,51 \\
Duration and distribution of weekly encounters & 3,97 \\
Number of students that attended the course & 4,03
\end{tabular}

Very Good - 5, Good - 4, Regular - 3, Unsatisfied - 2, and No Condition to Evaluate - 1

The proposal of the next course will try to settle difficulties distributing the schedule load in three trimesters and previously announce the synchronous activity timetable.

\section{SisWeb project}

The SisWeb project consists of the development and attendance of a special course based on the TELEDUC web learning environment in the Centro Estadual de Ensino Supletivo (CEES) in Cruz Alta (Brazil) for the graduation programs known as non-formal learning courses.

The non-formal learning aims to render the opportunity favourable for young and old people to conclude their studies (in grade school and high school) through alternative educational systems. As long as the student is considered capable in all disciplines, which compose grade school and/or high school, he or she receives certification and can carry out with his or her studies.

The CEES in partnership with the Cultural and Educational County Offices along with local companies reach out to several towns in the state of Rio Grande do Sul. The CEES during 1999, graduated 201 grade school students and 259 high school students, being that around 1,250 students now benefit from this project.

The course material for SisWeb project was elaborated by Biology and Math teachers from UNICRUZ - Universidade de Cruz Alta, which participated in the elaboration of the presentation contents and models of this experiment with UFRGS.

The course is performed through educational modules and consists of 16 modules with at least one test per module. The student should obtain an average of 8.0 to pass in the module, which enables him to go on to the next.

Two classes for each discipline were used for the tests. One using the SisWeb learning environment while the others the traditional teaching, 
attending the equivalent of ten-hour classes in the SisWeb. The 14 Biology students had their performance compared with 16 night-attending students that frequented traditional classes. In the same way, 12 daytime math students used the system and had their performance compared with 20 night students (as we can see, the number of students per class cannot be the same).

\section{Results}

The attained results with the SisWeb through tests, just the same for both classes, are as shown in Table 3.

Table 3. Students evaluation results

\begin{tabular}{lcc}
\hline \multicolumn{1}{c}{ Class } & Evaluated students & Average \\
\hline T7 - morning (with SisWeb) & 14 & 82,80 \\
T7 - night (no SisWeb) & 16 & 87,50 \\
T7 - afternoon (with SisWeb) & 19 & 80,79 \\
T7 - night (no SisWeb) & 20 & 85,62 \\
\hline
\end{tabular}

The attained information revealed a better performance, as much as in Biology as in Math, among the students that studied with a constant support of a teacher. But some factors contributed to that result, such as:

- Greater frequency of night time students than daytime students;

- Lack of previous know-how on handling a computer;

- Only ten computers were available in each computer lab.

The main difficulties found in the use of the teaching system lies in the computer's domain, due to the fact that many students had little knowledge on how to deal with computers got in the classes way and consequently the learning. Other negative factors were the lack of space where three students had to use one computer together. Despite these problems, it verified the students' enthusiasm with the idea of working with a computer to learn, having in mind their curiosity and the possibility of being in contact with new technologies.

This study show us that for the utilization of a distance learning system, it is necessary for the users' to have good knowledge about the computer, which would increase the production and exploitation of a tool. In this second experiment, the students were not familiar with computers. 


\section{CONCLUSIONS}

The idea of self-learning is more crucial for distance education than in conventional teaching, where the interactions between teachers and students and among students promote permanent motivation. The students' success in distance education really depends on self-motivation.

The problems generated by the separation in time require differentiated attention. Strictly, the problems caused by the separation in space can be easily overcome through efficient personal simultaneous communication systems or differentiated between the students, tutors and teachers, and among the students themselves.

The first great challenge to be faced by the institutions refers more to an affective-associate matters instead of the contents or methods. Contact and interaction strategies with students become more relevant: monitors providing prompt answers, teachers acting in a synchronous way and motivated students are indispensable conditions for success in a course.

Many students encounter difficulties in reaching the autonomous demands in their learning, time management, planning and self-direction set by the autonomous learning. Distance education will succeed when it involves interaction/interactivity between teachers and students, between students and the learning environments, and among the students. As for the statistical results as shown above, we intend to verify both case studies with a bigger number of students during 2003.

\section{ACKNOWLEDGEMENTS}

The projects described here, were sponsored by FAPERGS and CNPq. We also thank SisWeb and the Espie team.

\section{REFERENCES}

Eysenck, M. and Keane, M. (1994) Psicologia Cognitive: um manual introdutório. Porto Alegre: Artes Médicas.

Mizukami, M.G. (1977) Ensino: As abordagens do processo. São Paulo: EPU.

Piaget, J. A (1977) Psicologia. Lisboa, Bertrand.

Rosemberg, M. J. (2001) E-Learning: strategies for delivering knowledge in the digital age. New York. McGrawHill. 
Sherry, L. (1981) Issues in Distance Learning. International Journal of Distance Education, v.1, n.4, p. 337-365, 1996.

[http://www.cudenver.edu/public/education/sherry/pubs/issues.html]

Simon, H. (1981) As Ciências do artificial. Coimbra, A. Amado.

Vicari, R.M, et al. (2003) A multi-agent intelligent environment for medical knowledge, Artificial Intelligence in Medicine (702) 1-32.

Giraffa L.M.M. and Vicari, R.M. (1999) Modelling an interactive ITS using a MAS approach: from design to pedagogical evaluation. In: Proceedings of the Third International Conference on Computational Intelligence and Multimedia Applications, ICCIMA'99, Nova Delhi, 1999, Delhi: IEEE Computer Science. 153-8.

Silveira R, and Vicari, R.M. (1999) Distance learning: from the intelligent tutor paradigm to a multi-agents architecture. In: San Diego SCS, Bruzzone AG, Ulrmacher Page EH, editors. Proceedings of the WEBSIM'99 - International Conference on Web-Based Modelling and Simulation, San Francisco, CA.

Schwartz B.B, and Neuman Y, Gill J, Ilya M. (2001) Effects of argumentative activities on collective and individual Learning - Euro - CSCL 2001, Maastricht, 22-24. 